\title{
16. Contrasting Dual-Use Issues in Biology and Nuclear Science
}

\author{
Nicholas G. Evans
}

\section{Dual use and nuclear science}

The so-called 'dual-use dilemma' — which arises when scientific research, materials or technologies can be used to both benefit and harm humanity ${ }^{1}$ - is not an altogether new phenomenon. Early in the twentieth century, nuclear science-here, the study of the properties of atomic nuclei-raised similar concerns about materials, technologies and knowledge that had the potential to be used to benefit humanity, but also posed serious risks of misuse. Comparing the experiences of the nuclear sciences with those of biology in regulating dualuse materials, knowledge and technology will be the focus of this chapter.

Nuclear science raises a number of dual-use issues. Nuclear science has many beneficial uses, the best known being nuclear-fission (the process by which a nucleus is split into two or more smaller parts) reactors. These reactors are useful in power generation, and are also used to create radioisotopes - elements that are subject to radioactive decay that have a variety of uses described below. Nuclear fusion (the process of 'fusing' two lighter nuclei into a heavier nucleus) is currently being explored as a cleaner, more plentiful fuel source that could become an important source of energy in years to come.

Non-fissile radionuclides - radioactive substances not capable of energetic fission-have a range of useful and beneficial medical, agricultural, construction, military and aviation applications, to name a few. Radioisotopes have therapeutic applications in medicine, as their emissions can be used to bombard and kill cancerous cells with radiation. Radioisotopes are also used in diagnostic testing, for example, where the emissions of ingested radioisotopes are plotted to gain information about physiological processes. In agriculture, radionuclides are used to create blight or weather-resistant crops, and kill parasites in food storage. In construction, radioisotopes are used to verify the

\footnotetext{
1 This corresponds with a common definition of dual use, such as that found in Miller and Selgelid. It, as others have discussed previously, does not deal with all definitions of the dual-use dilemma, but for the purposes of this chapter I restrict my analysis to the explicitly normative definition of dual use. See Miller, S. and Selgelid, M. J. 2008, Ethical and Philosophical Considerations of the Dual-Use Dilemma in the Biological Sciences, Springer, Dordrecht; Selgelid, M. J. 2010, 'Ethics engagement of the dual-use dilemma: progress and potential', in B. Rappert (ed.), Education and Ethics in the Life Sciences, ANU E Press, Canberra, pp. 23-34.
} 
integrity of metals by detecting the scattering of emitted particles to determine the internal structure of metal or concrete under load. Depleted uranium - a byproduct of the enrichment process where the uranium-235 used in nuclear weapons and reactors is separated from non-fissile uranium-238 - is incredibly dense and malleable, making it an ideal form of armor plating in tanks. In aviation, depleted uranium is used to weight propeller rotors. Depleted uranium also provides an ideal form of radiation shielding in reactors due to its high rate of capture of alpha, beta and gamma radiation, as well as neutrons. A layer of depleted uranium in a reactor can function as reactor shielding, and, as the depleted uranium captures neutrons and is converted into plutonium, can be used as reactor fuel.

The study of the atom in nuclear science and its connection to quantum mechanics and materials science have also led to the development of the materials and electronics that presently dominate the technological landscape. Many scientific innovations that are now ubiquitous in contemporary society (for example, the personal computer) owe their genesis to the pioneers of nuclear physics.

Nuclear science also has well-known harmful uses that pose a risk of being used by malevolent actors. Nuclear fission is the driving mechanism behind the atomic bombs dropped on Hiroshima and Nagasaki. Nuclear fusion is the mechanism that, combined with fission, drives the 'super' or H-bomb. Contemporary research into either nuclear fission or nuclear fusion can enable the creation and development of these weapons.

Many radioisotopes are highly toxic and can cause radiation sickness if ingested by or embedded in a person for an extended period. Radioisotopes packed around conventional explosives, known as 'dirty bombs', can cover a large area in radioactive ash. Survivors of such a blast would have to deal with radioactive particulates embedded in their bodies as a result of the explosion, infrastructure affected would need decontamination or have to be destroyed and removed, and the treatment requirements and potential for contamination in caring for the injured would increase significantly. ${ }^{2}$ Radionuclides can cause radiation poisoning or other health problems if released - accidentally or intentionallyinto water supplies, or as a gas or powder. The murder of former KGB agent and defector Alexander Litvinenko, who died of radiation poisoning after ingesting significant amounts of polonium-210, is an example of malevolent uses of radioisotopes. $^{3}$

2 For example, Zimmerman, P. D. and Loeb, C. 2004, 'Dirty bombs: the threat revisited', Defense Horizons, vol. 38, pp. 1-11.

3 Stoll, W. 2007, '210-polonium', Atw. Internationale Zeitschrift für Kernenergie, vol. 52, no. 1, pp. 39-41. 


\section{Wither nuclear science?}

Despite the dual-use potential of nuclear science, there has been little examination of the parallels between nuclear science and biology in current debates about the dual-use dilemma. ${ }^{4}$ One important reason is that, from the outset, discourse has neglected or downplayed the relevance of the nuclear sciences to the debate in the life sciences. In 2004, a canonical report by the National Research Council chaired by Gerald Fink titled Biotechnology Research in An Age of Terrorism (the 'Fink Report') stated:

The nature of the biotechnology problem - indeed the nature of the biological research enterprise - is vastly different from that of theoretical and applied nuclear physics in the late 1930s. The contrast between what is a legitimate, perhaps compelling subject for research and what might justifiably be prohibited or tightly controlled cannot be made a priori, stated in categorical terms, nor confirmed by remote observation. ${ }^{5}$

The Fink Report argued that the primary mechanism of arms control in the case of nuclear weapons, materials control, is not applicable to the life sciences. ${ }^{6}$ The report highlighted differences between the properties of nuclear fissile materials and biological pathogens, which it claimed rendered materials control impractical as a regulatory solution (Table 16.1).

A follow-up report in 2006, Globalization, Biosecurity, and the Future of the Life Sciences (the 'Lemon-Relman Report'), gave a similar argument to the Fink Report regarding dual use:

Clear thinking on the issue must proceed from an understanding of the significant differences among [biological and nuclear] weapons. Although there are lessons to be learned from the history of and our experience with nuclear weapons technology, many of the differences between the nuclear and biological realms are too great to adopt a similar mix of nonproliferation, deterrence, and defense. ${ }^{7}$

\footnotetext{
4 Notable exceptions include Selgelid, M. J. 2007, 'A tale of two studies: ethics, bioterrorism, and the censorship of science', The Hastings Centre Report, vol. 37, no. 3, pp. 35-48; Finney, J. L. 2007, 'Dual use: can we learn from the physicists' experience?' in B. Rappert (ed.), A Web of Prevention: Biological Weapons, Life Sciences and the Governance of Research, Earthscan, London, pp. 67-76; Forge, J. 2008, The Responsible Scientist, University of Pittsburg Press, Pittsburg; Miller and Selgelid, op. cit.

5 National Academies of Science 2004, Biotechnology Research in An Age of Terrorism, The National Academies Press, Washington, DC, p. 23.

6 Ibid., pp. 81-3.

7 National Academies of Science 2006, Globalization, Biosecurity, and the Future of the Life Sciences, The National Academies Press, Washington, DC, p. 46.
} 
On the Dual Uses of Science and Ethics

Table 16.1 Characteristics of Fissile Materials and Pathogens

\begin{tabular}{|l|l|}
\hline Fissile materials & Biological pathogens \\
\hline Do not exist in nature & Generally found in nature \\
\hline Non-living, synthetic & Living, replicative \\
\hline Difficult and costly to produce & Easy and cheap to produce \\
\hline $\begin{array}{l}\text { Not diverse: plutonium and highly enriched } \\
\text { uranium are the only fissile materials used in } \\
\text { nuclear weapons }\end{array}$ & $\begin{array}{l}\text { Highly diverse: more than } 20 \text { pathogens are } \\
\text { suitable for biological warfare }\end{array}$ \\
\hline $\begin{array}{l}\text { Can be inventoried and tracked in a } \\
\text { quantitative manner }\end{array}$ & $\begin{array}{l}\text { Because pathogens reproduce, inventory } \\
\text { control is unreliable }\end{array}$ \\
\hline $\begin{array}{l}\text { Can be detected at a distance from the } \\
\text { emission of ionising radiation }\end{array}$ & $\begin{array}{l}\text { Cannot be detected at a distance with } \\
\text { available technologies }\end{array}$ \\
\hline $\begin{array}{l}\text { Weapons-grade fissile materials are stored at } \\
\text { a limited number of military nuclear sites }\end{array}$ & $\begin{array}{l}\text { Pathogens are present in many types of } \\
\text { facilities and at multiple locations within a } \\
\text { facility }\end{array}$ \\
\hline $\begin{array}{l}\text { Few non-military applications (such } \\
\text { as research reactors, thermo-electric } \\
\text { generators, and production of radioisotopes) }\end{array}$ & $\begin{array}{l}\text { Many legitimate applications in biomedical } \\
\text { research and the pharmaceutical/ } \\
\text { biotechnology industry }\end{array}$ \\
\hline
\end{tabular}

Source: National Academies of Science 2004, Biotechnology Research in An Age of Terrorism, The National Academies Press, Washington, DC.

The above conclusion - echoing the Fink Report-indicates that, due to the marked differences between the materials in question, methods of prevention used in the nuclear sciences are unsuitable to regulate biological science and technology. Moreover, the current culture of biology is not one that is conducive to these regulations.

Yet, I wish to contend, the lack of immediate compatibility between regulatory measures does not entail that the differences between fields are too great for anything valuable to be learned from nuclear history when reflecting upon how dual-use biology should be governed. It is doubtful that the regulatory framework used in nuclear sciences would provide a good model to use even if biology and nuclear sciences were more similar. No-one wants another arms race. That said, even just the lessons learned from the regulatory and policy mistakes in the nuclear sciences would be useful-but I hope to show that we can learn far more than that.

The purpose of this chapter is to compare and contrast regulation of the dual-use dilemma in the nuclear and biological sciences. This will not be a comprehensive comparison - the history of the nuclear sciences from its beginning in the early twentieth century through to the political implications of nuclear science in the twenty-first century is too large for a single chapter. Rather, I will provide a series of examples from the nuclear sciences that invites exploration of different ethical issues of dual use in the life sciences. I also view this chapter as a call for 
further investigation of the nuclear sciences and their history to understand the pitfalls of regulating science and technology, and apply lessons learnt to dual use in the life sciences.

Finally, it is not my intention to claim that biology and the nuclear sciences are the same regarding the dual-use dilemma. I will show where the issues presented by dual-use materials, knowledge, techniques or technologies in each field overlap, and where they come apart. The differences between nuclear science and biology do not preclude an analysis of their similarities; likewise, those differences may be important in and of themselves.

Second, the examples I have chosen serve to highlight some less-explored features of the dual-use dilemma in the life sciences-features I believe deserve significant exploration. Though we may continue to worry about the potential for state-sponsored biological weapons programs, a primary concern in the dual-use dilemma is that of small groups or individuals committing acts of bioterrorism. My examples are chosen to identify issues in regulating these small-scale operations. This does not mean that there is nothing to be learned from the nuclear sciences about state-level regulations, or that my analysis doesn't cover these issues at all. Rather, my focus is meant to target the trajectory I see the (rapidly) evolving life sciences following, in an effort to identify issues that will arise or are already coming to light regarding dual-use research.

\section{Materials control}

Materials control is an important part of preventing the misuse of science and technology. If access to the constituent materials of biological or nuclear weapons is restricted, their use can be restricted presumably to good uses by good and responsible actors. As the subject of the Fink Report that led to their conclusion that the nuclear sciences cannot inform our thought on the dual-use dilemma, materials control is a good first point of inquiry for this chapter. The differences between fissile materials and biological pathogens listed in Table 16.1 are a paradigmatic way of contrasting nuclear science and biology. The differences between the materials used in both fields present a picture in which nuclear science is far removed from biology.

There are definitely some pathogens that possess the same type of threat as nuclear weapons. A smallpox attack could potentially cause up to 167000 deaths - greater than the number who died when the United States dropped a nuclear weapon on Hiroshima. ${ }^{8}$ An anthrax attack on an unprepared population could cause more than half a million deaths, but only if the emergency response

8 See Samuel, G., Selgelid, M. J. and Kerridge, I. 2010, 'Back to the future: controlling synthetic life sciences trade in DNA sequences', Bulletin of the Atomic Scientists, vol. 66, p. 10. 
to the act was mismanaged. ${ }^{9}$ The botulinum toxin - a biological toxin and the most potent poison in the world-released into the milk supply of the United States could kill up to 200000 people, the majority children or the elderly. ${ }^{10}$ Most recently, there are concerns that genetically modified avian influenza could kill millions. ${ }^{11}$

Those listed above, however, are some of only a few pathogens capable of the devastation similar to that visited on Hiroshima. Moreover, comparisons to Hiroshima are dated and misleading: the W76 warhead, a mainstay of the US nuclear arsenal, has a yield of 100 kilotons, ${ }^{12}$ roughly five times that of the Hiroshima bomb. The W76 bomb is, further, small in yield compared with others in the US and Russian arsenals. Nuclear weapons range from 'tactical' warheads of a fraction of a kiloton, to megaton (where one megaton is equivalent to 1000 kilotons) scales. ${ }^{13}$

Biological attacks, further, suffer from a greater range of contingencies than nuclear attacks, and are prone to more variable yields than nuclear weapons. Bad weather - or, in the case of spores that are sensitive to sunlight, good weathercan seriously mitigate the effect of a bioweapons attack, to say nothing of other factors. Damage caused by biological weapons can be further mitigated by strong public health policies, smart post-attack vaccinations, and so on. ${ }^{14}$ This is contrasted with the indiscriminate and destructive nature of nuclear weapons, which are more or less impervious to weather conditions or most attempts to defend against them.

This is not to say that biological pathogens should be treated less seriously than fissile materials. A key difference listed in the Fink Report is that the destructive potential of nuclear weapons is balanced to an extent by the difficulty of procuring fissile materials. Bioweapons, on the other hand, are likely to be more attainable and more augmented for causing death in years to come. For the most part, however, the distinction between the (broad) class of things called

9 Wein, L. M., Craft, D. L. and Kaplan, E. H. 2003, 'Emergency response to an anthrax attack', Proceedings of the National Academies of Science, vol. 100, no. 7, pp. 4346-51. It is worth, in the interest of disclosure, noting that 660000 people are predicted to die in the modelled attack in the case where only individuals symptomatic with the disease are given antibiotic treatment. Wein et al. are quite clear in their study that there are a number of factors that, taken together, could lower this death count to approximately 10000.

10 Wein, L. M. and Liu, Y. 2005, 'Analyzing a bioterror attack on the food supply: the case of botulinum toxin in milk', Proceedings of the National Academies of Science, vol. 102, no. 28, pp. 9984-9.

11 Enserink, M. 2011, 'Grudgingly, virologists agree to redact details in sensitive flu papers', Science Insider, 20 December 2011, <http://news.sciencemag.org/scienceinsider/2011/12/grudgingly-virologists-agree-to. html > (viewed 1 February 2012).

12 Where 1 kiloton $=1000$ tonnes of TNT equivalent energy of explosion.

13 Norris, R. S. and Kristensen, H. N. 2007, Estimates of the U.S. Nuclear Weapons Stockpile [2007 and 2012], $<$ http://www.fas.org/programs/ssp/nukes/publications1/USStockpile2007-2012.pdf> (viewed 24 February 2010).

14 See, for example, Wein et al., 2003, op. cit.; Chen, L.-C. et. al. 2004, 'Aligning simulation models of smallpox outbreaks', Intelligence and Security Informatics, vol. 3073, pp. 1-16; Wein et al., 2005, op. cit. 
'biological pathogens' and the (narrow) class of things called 'fissile materials' is inaccurate; we are working with two classes of materials for which the comparisons we can make are not strong ones.

\section{Radionuclides}

A better comparison, I contend, is between biological pathogens and radionuclides described above. Though radionuclides more generally are not dual-use materials of the same degree as fissile materials - which form a small but significant set of radionuclides - radionuclides generally pose a series of dual-use issues, some of which I have described above.

Radionuclides are significant for two reasons. First, much as we think there are dual-use issues with life-sciences materials, technology and research that are worthy of attention even though they are not dangerous on the scale of, say, weaponised smallpox, there are dual-use issues in the nuclear sciences that do not involve nuclear weapons. Second, the way fissile materials were and are regulated is, as the Fink Report argued, somewhat unique. It is useful to examine the regulation of other areas of the nuclear sciences, which may have experienced issues with regulation more in line with what we would expect from the life sciences.

Though nowhere near as powerful as a thermonuclear detonation, or the expert use of weaponised smallpox, dirty bombs would cause damage comparable with less spectacular - and paradigmatic - examples of bioterrorism. First, the 'Amerithrax' attacks that occurred following the 11 September 2001 attacks on the World Trade Centre killed five and infected a further 17 people. Second, the attempted attack by the Aum Shinrikyo cult through the dispersion of anthrax failed, ${ }^{15}$ but could have easily inflicted hundreds of casualties had it worked; the Sarin gas attack in 1995 on the Tokyo subway by the same cult killed 12 and injured thousands. ${ }^{16}$ Finally, the lacing of salad bars with salmonella by the Bagwasrinesh cult in Oregon did not kill anyone, but hospitalised 45 and infected $750 .{ }^{17}$ These cases are of serious concern, but the number of casualties (or hospitalisations, in those cases that lacked fatalities) is much smaller than from a thermonuclear explosion.

Sufficient exposure to radioisotopes can also lead to radiation poisoning. The most high-profile recent case of this is the death of KGB defector Alexander Litvinenko from a lethal dose of polonium-210. Polonium-210 is found in

15 See, for example, Miller, J., Broad, W. and Engelberg, S. 2001, Germs: Biological Weapons and America's Secret War, Simon \& Schuster, New York.

16 Tu, A. T. 1999, 'Overview of the sarin terrorist attacks in Japan', in A. T. Tu and W. Gaffield (eds), Natural and Selected Synthetic Toxins: Biological Implications, ACS Symposium Series, 20 December, pp. 304-17.

17 Miller et al., op. cit. 
antistatic brushes used in photography, and in the United States is sold in quantities large enough to be used to administer a fatal dose to someone. Large quantities of powdered radionuclides, even those that emit alpha radiation (which is typically considered harmless as it cannot penetrate the skin), distributed in a water supply could cause significant harm.

The malevolent use of radionuclides in dirty bombs or as poisons makes many industrial, medical and commercial technologies dual use. Determined terrorist groups presently could accrue large amounts of radionuclides through looting old or abandoned radiotherapy devices. ${ }^{18}$ In 1987, for example, two men stole a capsule containing caesium-137 from an abandoned hospital site in Goiânia, Brazil. ${ }^{19}$ The amount of caesium they stole would cause a significant number of casualties and economic damage if used in a dirty bomb. It is believed that a terrorist organisation would be able to easily procure quantities of radionuclides similar to those in Goiâna, if not larger amounts, through the purchase of radioactive refuse or radionuclides from former Soviet states that once functioned as disposal sites for highly radioactive nuclear waste. ${ }^{20} \mathrm{UN}$ inspectors have raised concerns that there are still highly problematic quantities of unguarded, unaccounted for radiological material in the world..$^{21}$

One might object that the issues involved with securing biological pathogens are not the same as those with radionuclides. After all, influenza if left absent a host can die out relatively quickly, whereas caesium-137 will continue to exist and decay with a half-life of approximately 30 years until, via beta and gamma decay, it has turned into the stable barium-137. I don't deny that there are differences in the practicalities of securing different types of dual-use material-but this is both within and between fields. What is more interesting are the challenges presented by attempts to subvert regulations, especially when we consider materials that-befitting their classification as dual use-are used in public, commercial or industrial applications.

\section{Acquiring materials piecemeal}

Even if existing large sources of radioactive material were secured there is a possibility that someone could acquire significant nuclear materials to, for example, create a dirty bomb by acquiring dangerous radionuclides piecemeal. By this, I mean that dangerous radioactive compounds could be acquired in

18 Zimmerman and Loeb, op. cit.; International Atomic Energy Agency (IAEA) 2002, Inadequate Control of World's Radioactive Sources, <http://www.iaea.org/newscenter/pressreleases/2002/prn0209.shtml> (viewed 24 February 2011).

19 International Atomic Energy Agency (IAEA) 1988, The Radiological Accident in Goiânia, <http://wwwpub.iaea.org/mtcd/publications/pdf/pub815_web.pdf> (viewed 24 February 2011).

20 Zimmerman and Loeb, op. cit.

21 IAEA, 2002, op. cit. 
quantities small enough or clandestine enough to avoid the oversight of a body like the Nuclear Regulatory Commission (NRC). To illustrate this, consider the case of David Hahn, who at seventeen years of age, attracted the attention of the NRC and the Environmental Protection Agency for acquiring dangerous amounts of radium, americium and thorium, when he irradiated his mother's potting shed in an attempt to create a nuclear breeder reactor. ${ }^{22}$ Though radium and americium are both problematic, as they could be used in a dirty bomb, David's acquisition of significant quantities of thorium is especially worrisome, as thorium-232 can be converted into uranium-233, a fissile material.

Hahn failed in his attempts to create a reactor (breeders require liquid sodium as a heat-transfer mechanism and are notoriously difficult to create even in ideal, well-financed conditions). What he did succeed in was creating a highly active neutron source. Hahn's neutron source was made by encasing americium that he had extracted from smoke detectors (and, later, radium extracted from the paint used in antique clocks) in lead with a pinhole in it, and using a strip of beryllium to convert the alpha radiation from the americium/radium into neutrons. Hahn targeted his neutron source at a grid of thorium-232 bricks he had purified from the ash of the mantles of camping lanterns. His purification method was relatively sophisticated considering his resources; he heated bars of lithium sourced from lithium-ion batteries surrounded by the thorium ash, causing the thorium to reduce and lithium to oxidise, leaving lithium oxide ash and pure thorium. ${ }^{23}$

Hahn's story is important because it shows how little training and money are needed to extract radioisotopes from commonplace technologies. Smoke detectors, camping lanterns and antique clocks do not typically fall into the purview of 'dual-use technologies', and yet they were sufficient for a seventeenyear-old to acquire thorium in quantity and purity that he (had he bought the thorium) would have violated materials control regulations of the NRC; his experiment caused enough of a hazard to warrant a Superfund hazardous materials clean-up.

The case of David Hahn raises a problem of acquisition of materials from existing technologies and natural sources. Piecemeal acquisition of dual-use materials in the life sciences has already received some attention. ${ }^{24}$ There are common and naturally occurring viruses that could conceivably function as a natural template for a modified, virulent pathogenic organism. For instance, a potential terrorist could attempt to synthesise genetically modified influenza - a presently

\footnotetext{
22 See Silverberg, R. 2004, The Radioactive Boy Scout: The Frightening True Story of a Whiz Kid and his Homemade Nuclear Reactor, Random House, New York.

23 Ibid.

24 Samuel et al., op. cit. See also National Academies of Science 2010, Sequence Based Classification of Select Agents: A Brighter Line, The National Academies Press, Washington, DC.
} 
technically difficult proposition - or they could wait until flu season to gain living native samples and modify them. Anthrax, to use another example, is still a common disease amongst cattle in developing countries.

The advent of 'do-it-yourself' (DIY) or 'garage' biology, where individuals practise biology at home or in private hobby groups, further undermines the efficacy of materials control. As the cost of sequencing and synthesis continues to decline, and the methods of DIY biologists in procuring samples either individually or through communal open labs ('biological commons') or creating their own technologies become increasingly sophisticated, ${ }^{25}$ materials control will become progressively more costly, or even completely ineffective. Current regulatory approaches should take this into account when attempting to design overlapping regulatory measures - the so-called 'web of prevention' ${ }^{26}$ - to prevent the misuse of biotechnology.

Moreover, if present expectations for biology are fulfilled, biological materials stand to become a ubiquitous part of modern lifestyles not in the way of nuclear materials, but in the way of microchips. ${ }^{27}$ Many of these biological materials will not pose a significant dual-use threat, but there is a good chance that many of them will. Understanding how biological materials will appear in the everyday world and how motivated individuals might use them for malevolent or just manifestly reckless purposes is an important step in understanding dual use beyond the paradigm of state-level weapons conventions, deterrence and a fieldwide security enterprise - a paradigm that is already recognised as untenable or insufficient for the dual-use threat in the life sciences.

\section{Restricting access to technology}

Another regulatory option is to restrict access to dual-use technologies. Biological technologies such as modern DNA sequencers have serious dual-use potential. DNA sequencers are able to sequence code in aid of doing beneficial research or creating non-pathogenic varieties of viruses for study or medicine; however, they may also find use in developing pathogens for use in harming others - for example, in manufacturing novel or existing pathogens to use in biological weapons.

\footnotetext{
25 See Carlson, R. 2010, Biology is Technology: The Promise, Peril, and New Business of Engineering Life, Harvard University Press, Cambridge, Mass.

26 Feakes, D., Rappert, B. and McLeish, C. 2007, 'Introduction: a web of prevention?' in B. Rappert and C. McLeish (eds), A Web of Prevention: Biological Weapons, Life Sciences and the Future Governance of Research, Earthscan, London, pp. 1-14.

27 See Carlson, op. cit.
} 
Restricting access to technologies, much like materials control, is no less sure a strategy than materials control against talented, curious or motivated individuals. Famously, in 1976, Dr Abdul Qadeer Khan stole the plans for a centrifuge from his workplace at Urenco in the Netherlands. This theft, and Khan's later work, would ultimately mark the genesis of the Pakistani atomic weapons project. ${ }^{28}$ In today's communicative environment, there are many more opportunities for determined individuals like Khan to enable the proliferation of technologies. The ubiquity of portable electronic storage devices and the potential of online so-called 'cloud' storage today make information containment very difficult.

In weighing the benefits created by restricting technologies against the costs of such policies, we must also account for the possibility that determined individuals, as in the case of David Hahn, will simply adopt indigenous or DIY methods to achieve their goals. This is already an emerging phenomenon in biology; 'garage biologists' have created DIY and low-cost solutions to expensive technologies in biology, such as Lava Amp, a low-cost, USB-powered PCR thermocycler. ${ }^{29}$ For those devices that can't be made at a low cost, secondhand laboratory equipment is now available online. The sophistication and availability of low-cost or DIY biological laboratory tools are only likely to increase in the near future.

The creativity and drive to create lower-cost, more accessible tools in biology are surely things to be valued, for their own sake and for the gains we could have with a larger and more accessible research culture. This rapid lowering of access barriers to technologies, however, comes at a cost to security. That is, as biological technologies become ubiquitous, indigenous approaches to dual-use technologies will emerge as much from small enterprises as from large projects. While in the nuclear sciences, it required a state to manufacture indigenous technologies where restrictions on dual-use technology were already in place, individuals may conceivably be able to manufacture their own technologies.

These gains through low-cost, accessible technologies are surely not the only things we value. These gains must still be weighed against other things we value, such as our collective wellbeing, how that collective wellbeing is distributed (that is, equality), if those who are harmed as a result had the capacity to understand the risks of the proliferation of these technologies and consent to their proliferation (that is, fairness), and how tightly we think these matters should be regulated in the public interest (that is, liberty). Running roughshod over these complex ethical issues reduces us to a simple appeal to utility, and

28 See Corera, G. and Myers, J. J. 2006, Shopping for Bombs: Nuclear Proliferation, Global Insecurity, and the Rise and Fall of A. Q. Khan's Nuclear Network, Oxford University Press, London.

29 'Lava Amp', <http://www.lava-amp.com/> (viewed 27 February 2011). 
a narrow sense of utility at that. Most of us, reflecting on the nuclear sciences, would admit that the nuclear sciences, even if they have brought gains to our lives, have brought gains unequally and at times unfairly.

\section{Restriction of information}

At times, it may be that the knowledge produced by a particular piece of research is dual use. The polio virus case, for example, functioned as a 'proof of principle' that viruses could be synthesised de novo. This is independent of which virus - or strain of a particular virus - is to be synthesised. It means that vaccines could be constructed rapidly, but also that virulent pathogens could be made. Even then, this could be good, enabling more individuals to study a virus with an eye to creating medicines against it; however, the knowledge could be also used to harm others. Jeronimo Cello and Eckard Wimmer, two of the researchers who worked on the polio virus synthesis, noted that one of the important outcomes of the research was confirming that viruses, in fact, behave in a chemical fashion and can be synthesised like chemicals. ${ }^{30}$ It is this knowledge, we might think, which is dangerous as much as any physical materials used in the research.

One option is to censor information. We could restrict what projects are undertaken, or we could restrict - either temporarily or permanently, depending on the seriousness of the dual-use concern - the publication of research. For example, a 2005 study in the Proceedings of the National Academies of Science modelling a terrorist attack in which botulinum toxin was released in the US milk supply was embargoed for approximately a month as the journal, the National Academy of Sciences and government officials debated the security concerns in releasing such a report. ${ }^{31}$ In 2011, the National Science Advisory Board for Biosecurity (NSABB) recommended the censorship of two studies in which highly pathogenic $\mathrm{H} 5 \mathrm{~N} 1$ avian influenza virus was modified to be transmissible between ferrets (close immunological analogues to humans), though this recommendation was later reversed. ${ }^{32}$

Regulating the production of such knowledge by restricting its creation or its dissemination is typically met with suspicion or outrage. Denying scientists

\footnotetext{
30 Selgelid, M. J. and Weir, L. 2010, 'Reflections on the synthetic production of poliovirus', Bulletin of the Atomic Scientists, vol. 66, no. 3, pp. 1-9.

31 Alberts, B. 2005, 'Modeling attacks on the food supply', Proceedings of the National Academy of Sciences, vol. 102, no. 29, pp. 9737-8. See also Wein, L. M. 2008, 'Homeland security: from mathematical models to policy implementation: the 2008 Philip McCord Morse lecture', Operations Research, vol. 57, no. 4, pp. 801-11.

32 Evans, N. G. 2013, 'Great expectations - ethics, avian flu and the value of progress', Journal of Medical Ethics, vol. 39, pp. 209-13.
} 
their right to freedom of speech and their right to freedom of intellectual inquiry is seen as depriving them of basic rights. Moreover, there is concern that censorship or restriction of knowledge will not only deprive scientists of their rights, but also prevent beneficial research from occurring. Until the avian flu recommendation, scientific self-censorship was considered the norm for regulation of dual-use information. ${ }^{33}$

Though an important consideration, it would be a mistake to take self-governance on its own as a feasible regulatory strategy; no field demonstrates this more aptly than the nuclear sciences. For example, in 1939, Enrico Fermi, working with Szilard, showed that a nuclear chain reaction was experimentally possible. Szilard pressed Fermi at Columbia University and Frederic Joliot in Paris to keep their results secret. Fermi agreed hesitantly to comply on the condition that others followed suit, ${ }^{34}$ but Joliot's team rejected Szilard's proposal, Joliot stating that if he withheld publication an implication would be that 'Hitler ... succeeded in destroying another precious liberty'. ${ }^{35}$

Following publication of this information in May 1939, a September meeting of the German military began an investigation into the plausibility of a chain reaction leading to weapons ${ }^{36}$ and banned exports of uranium from Germancontrolled Czechoslovakia, effectively beginning the arms race for the bomb. ${ }^{37}$

This is a prime example of why relying on self-imposed censorship of resultsthe kind mentioned in contemporary reports on the dual-use dilemma ${ }^{38}$ is problematic. When regulatory measures are self-imposed without a way of binding members of a community to a decision, single individuals can undermine the greater projects of a community without good justification. Most of us would, I think, say that Joliot was unjustified in his assessment of the situation - surely if Hitler had succeeded in creating atomic weapons, more than just Joliot's liberty to publish would have been at risk.

Admitting that scientific self-censorship is not enough, there is genuine concern about permitting government control over scientific information. Allowing governments to control scientific information can be both ineffective and prone to abuse. For example, in 1979, the Department of Energy and the US Government attempted to censor the Progressive magazine and suppress information relating to the construction of the hydrogen bomb. This censorship was attempted under the auspices of the 'born secret doctrine', a policy of

\footnotetext{
33 National Academies of Science, 2004, op. cit., p. 101.

34 Rhodes, R. 1995, The Making of the Atomic Bomb, Simon \& Schuster, New York, p. 295.

35 Goldsmith, M. 1976, Frédéric Joliot-Curie: A Biography, Lawrence \& Wishart, London, p. 74.

36 Powers, T. 2000, Heisenberg's War: The Secret History of the Atomic Bomb, Penguin Books, London, p. 65.

37 Weart, S. 1976, 'Scientists with a secret', Physics Today, vol. 29, no. 2, p. 28.

38 For example, National Academies of Science, 2004, op. cit. See recommendation three of the Fink Report.

See also recommendations three and four of National Academies of Science, 2006, op. cit.
} 
secrecy in the Atomic Energy Act of 1954, restricting: 1) the design, manufacture or utilisation of atomic weapons; 2) the production of special nuclear material (uranium-233 or 235 or plutonium in natural or enriched states); and 3) the use of special nuclear material in the production of energy. ${ }^{39}$

The article of concern, written by Howard Morland, was based on information in the public domain. ${ }^{40}$ Morland had not, in writing his article, used any information that was secret. Much was still considered 'born classified', but had existed in the public domain long enough that it was more or less commonly accessible knowledge. The information of concern was the description of radiation implosion, the technical process that allowed the 'super'-better known as the hydrogen bomb - to operate. ${ }^{41}$

Morland's stated intentions in releasing the article were to promote discussion about the arms race and the extensive secrecy of the nuclear complex..$^{42}$ In this sense, the knowledge was used in a manner that many would consider to be good. Nuclear secrecy, while justified in certain areas, has been criticised for subverting discourse on arms reductions and control of nuclear weapons. ${ }^{43}$

The US Government's reasons for attempting to censor Morland's article were that public knowledge was not complete. Potential builders needed more than just what was publicly available-knowledge that Morland's article, they claimed, provided. The court, however, rejected this claim, stating that any deduction that Morland had made regarding the technical mechanisms of the hydrogen bomb were clearly independently deducible: four countries already had independently created hydrogen bombs.

\section{Lessons for biology}

The lesson of nuclear science is that restrictions on information, technology or materials are not, as is commonly described, tensions between freedom and control. Rather, the tension is all about control-namely, whose control should take priority. The above cases highlight the problems that arise when individual scientists or governments have unilateral control over the dissemination of information. Despite the increasing proliferation of information and communications technologies, we should resist the idea that individuals having

\footnotetext{
39 US Congress, The Atomic Energy Act of 1954, ss. 1-15.

40 Knoll, E. 1979, 'The "secret" revealed', The Progressive, vol. 43, pp. 1-2; Morland, H. 2005, 'Born secret', Cardozo Law Review, vol. 26, p. 1401.

41 Knoll, op. cit.; Morland, op. cit.

42 See 'Symposium on the progressive case', Cardozo Law Review, vol. 26, no. 4 (Special Issue 2005).

43 See, for example, Rotblat, J. (ed.) 1982, Scientists, the Arms Race, and Disarmament: A Pugwash/ UNESCO Symposium, Taylor \& Francis, London; Masco, J. 2002, 'Lie detectors: on secrets and hypersecurity in Los Alamos', Public Culture, vol. 14, no. 3, p. 441.
} 
unilateral control over the dissemination of scientific information is always better than allowing government control over some scientific information; and even if it is, that individual control is the best strategy all things considered.

Rather, we should aim to moderate between these two positions. What the balance between these two extremes should be is a live issue. Moreover, it is an ethical issue, not just one of efficiency or technical capacity to control information (though it surely is that as well). Yet just as we would deny the desirability of subjecting science to centralised, complete government control, we can deny the desirability of individuals making unilateral decisions about scientific information.

Further, we can broaden our view to include the views and concerns of citizens. Much of the debate around dual use stems from dual use being - by definitionbeneficial to humanity. Consulting humanity on what constitutes 'beneficial' would presumably be a step in the right direction. Morland's contention was that lacking in information due to the secrecy of the nuclear complex, the public was not able to engage with decision-making about the role of the nuclear sciences in public life. This, then, leads us to discussions about education.

\section{Education}

Education is advocated as a worthwhile strategy to deal with the dual-use dilemma. ${ }^{44}$ Typically, the proposed venues for ethics education are institutions of higher learning, where professional or apprentice practitioners can be trained in the ethical implications of their discipline. The aim of this education, then, is to engage bench scientists or students of science in the ethical issues associated with their research.

There are, however, other types of education that are crucial to mitigating the harms of the dual-use dilemma, as demonstrated by the nuclear sciences. These measures are associated with the education of the public in both ethics and scientific literacy. Recall that Morland's contention in the Progressive case was that public engagement and reasonable knowledge of the technical as well as the political aspects of the regulatory debates and structures in the nuclear sciences were necessary to functioning scientific policy.

Moreover, ordinary public citizens may at times be the only witnesses to problematic acts that are not the purview of conventional regulations. Without appropriate education, ordinary public citizens are not well placed to know what

44 See, for example, Rappert, op. cit.; National Science Advisory Board for Biosecurity (NSABB), Strategic Plan for Outreach and Education on Dual Use Research Issues, National Science Advisory Board for Biosecurity, Bethesda, Md. 
to look for or, sometimes, even what they are looking at. One of the observations that came from the David Hahn case is that, had they been suitably attentive, David's parents, teachers and classmates should have known something was amiss. Particularly at the point at which David began showing up with burns caused by exposure radiation, the public who interacted with David, we might think, should have become concerned enough to notify someone. ${ }^{45}$

Literature on dual use in the life sciences has discussed the merits - albeit to a lesser degree than the education of lab scientists - of public outreach. ${ }^{46} \mathrm{Such}$ outreach typically aims to create a culture of acceptance of novel technologies. The Biotechnology Industry Organization (BIO), for example, notes that 31 per cent of Americans surveyed by the Robert Wood Johnson Foundation are at least somewhat concerned about becoming ill from a bioterror attack. ${ }^{47}$ The aim of public outreach is often to calm fears about biotechnology, often by showing how the emerging science will contribute to security. ${ }^{48}$

Another reason to pursue extensive public education is that as the life sciences become ever more ubiquitous in the technological and social landscapes, the public's comprehension may become an important part of security. In the life sciences, this is particularly important as 'garage' or 'DIY' biology comes into its own. DIY biologists are biologists who pursue biological research from their homes, usually as a hobby or as part of an entrepreneurial activity. While DIY biologists can create communities that have strong commitments to safety and security, such as the organisation DIYBio, ${ }^{49}$ this is not a necessary-much less mandatory - part of being a DIY biologist. It remains to be seen how such a community can deal with members who would actively seek to cause harm, or perform reckless or dangerous experiments.

It may be that in some cases individuals engaged in DIY biology who pursue reckless or malevolent acts are only subject to observation by their peers, friends and family. In these cases, oversight is only plausible if those around an individual engaged in reckless or malevolent activity are suitably knowledgeable to recognise that something is amiss. If the public is not educated, activity done outside official laboratories may be overlooked with disastrous consequences.

Moreover, lack of public education may lead to powerful stakeholders dominating regulatory discourse in ways that are not conducive to the promotion of the good

\footnotetext{
45 See Silverberg, op. cit., ch. 8 and 'Epilogue'.

46 For example, Presidential Commission for the Study of Bioethical Issues 2010, New Directions: The Ethics of Synthetic Biology and Emerging Technologies, Washington, DC.

47 Biotechnology Industry Organization (BIO) 2010, Healing, Fueling, Feeding: How Biotechnology is Enriching Your Life, Biotechnology Industry Organization, Washington, DC, pp. 23-24, 29 n. 63.

48 Carlson, op. cit.; Carlson, R. 2003, 'The pace and proliferation of biological technologies', Biosecurity and Bioterrorism: Biodefense Strategy, Practice, and Science, vol. 1, no. 3, pp. 203-14.

49 'DIYBio', <http://diybio.org > (viewed 27 February 2011).
} 
of society as a whole. A longstanding criticism of the nuclear sciences is that regulatory debates were dominated by militant voices. ${ }^{50}$ In a similar fashion, much has been made recently of the potential for biology to create a new form of 'bio-economy' ${ }^{51}$ Without input from a range of actors, we might see money come to dominate the debate in the life sciences, much as the military came to dominate the debate in the nuclear sciences.

\section{Conclusion: From ethical comparison to ethical practice}

In this chapter, I have presented a number of cases that inform our thinking on issues created by, and issues that arise in dealing with, the dual-use dilemma. This, as I noted at the beginning of this chapter, is not a comprehensive account of the history of the nuclear sciences that might apply to the biological sciences. It is a snapshot to demonstrate the issues that can emerge from a comparison between the two, and lessons learnt about the success or failure of various attempts at regulation.

The above cases, I propose, provide four points that ought to guide our ethical practice

1. regulation of objects or information provides a barrier to access, but cannot be future-proof

2. the genius of the determined should not be underestimated - motivated and gifted individuals and groups will work around technical or political hurdles

3. restriction of information should seek to moderate between the risks of government and of self-imposed controls on information

4. education must focus on public education as well as the education of scientists. These recommendations are not particularly controversial, but nor should they be. The history of regulating the malevolent use of science and technology is one that is as old as science and technology. In addition to any suggestions that directly bear on the types of regulation we should adopt, nuclear science serves as a reminder of the pitfalls regulation can succumb to.

A common theme in these points is that - as the nuclear sciences learned the hard way-traditional regulatory arguments that pit absence of formal

\footnotetext{
50 Rotblat, op. cit.; Chan, A. H. 1993, 'Team B: the trillion-dollar experiment', Bulletin of the Atomic Scientists, vol. 49, no. 3, pp. 24-7, <http://www.channelingreality.com/NWO_WTO/Team_B_The_trilliondollar_experiment.pdf $>$ (27 February 2011).

51 Carlson, 2010, op. cit.
} 
regulation against absolute government control are deeply problematic. Nuclear science, I believe, tells us that all levels of stakeholder need to be engaged, most importantly the public. Public citizens are the end users and beneficiaries of biotechnology, and are likely to be victims of the accidents and misdeeds that motivate biosecurity debates. As biology becomes increasingly corporate and ubiquitous amongst private practitioners - the aforementioned 'garage' biologists - the public not only has the most to gain or lose from biology, but will also become witness to the misuse or abuse of biology and biotechnology. It is therefore imperative that regulation and biosecurity take into account the role the public will play.

This public education is surely to the benefit of everyone. For scientists, it presents an ever more educated public who values science and the benefits it brings. For a government, it presents a well-educated public who is better able to contribute to public life, and better able to understand the consequences of the misuse of biology, and react accordingly (for example, by supporting appropriate policy).

A better-educated public also provides the grounding for what I will refer to as 'open security'. As the pace of technological change increases, maintaining security will increasingly rely on surveillance, rather than attempting to build unwieldy regulations. In a world where the average personal computer can run complex simulations of nuclear weapons or epidemiological analysis; where desktop biological synthesis devices are not merely speculative but being discussed as real technologies; ${ }^{52}$ where individuals are endlessly and perpetually connected, debates about security must honestly weigh the tradeoffs and costs of restrictions to materials and information. As I have discussed often in this chapter, restrictions are not future-proof, and are only valuable when their benefits and costs are weighed against other important social goods. Increasingly, the cost of even small amounts of justified control ${ }^{53}$ is prohibitive. Life will overtake security if security does not become adaptive.

Finally, it is important to take a broader view of my analysis. First, I have argued that a number of the 'usual suspects' in regulation are problematic, but not necessarily regulatory methods particular to nuclear science. Current discourse in the life sciences, from the Fink Report on, still treats materials control, technology control, information control, education and so on as primary methods of controlling the dual-use threat. But these methods were not foolproof in the nuclear sciences; today they are almost invitations to practitioners in the life

52 Carlson, R. 2007, 'Laying the foundations for a bio-economy', Systems and Synthetic Biology, vol. 1, no. 3, pp. 109-17, <http://www.ncbi.nlm.nih.gov/pubmed/19003445>.

53 As opposed to unjustified amounts of control, which we might think is easier to affect, but costs a population much more. 
sciences to innovate around regulation. The nuclear sciences, in their failure to regulate the spread of dual-use technologies, should serve as a point of inquiry to figure out what doesn't work, and why.

Second, we should think beyond the nuclear sciences and begin drawing lessons of regulation from other technological cultures. If the genetic age stands to replace the information age, we should look at lessons learnt in the past 10 years of online culture to determine how regulation succeeded and failed to address the malevolent use of online technologies. The more information we can draw on, the more adaptive regulatory discourse can be.

Nuclear science is a broad and complex field with a long history. How much we can learn from it is as much a matter of how much care we take to investigate this history and apply lessons learnt to our current thinking and practice. As the debate over dual use in the life sciences is one in which we wish to prevent catastrophe, it seems prudent to take any source of guidance we can. Of those experiences in regulating science, none should be more important than the hard-earned lessons of nuclear science. 